\title{
Thermochemoradiotherapy Using Superselective Intra-arterial Infusion for Patients With Oral Cancer With Cervical Lymph Node Metastases
}

\author{
TOMOYO NOZATO ${ }^{1}$, TOSHIYUKI KOIZUMI ${ }^{*}$, YUICHIRO HAYASHI ${ }^{1}$, MASAKI IIDA $^{1}$, \\ TOSHINORI IWAI ${ }^{1}$, SENRI OGURI ${ }^{1}$, MAKOTO HIROTA $^{1}$, MITOMU KIOI $^{1}$, \\ IZUMI KOIKE ${ }^{2}$, MASAHARU HATA ${ }^{2}$, IWAI TOHNAI ${ }^{1}$ and KENJI MITSUDO ${ }^{1}$ \\ ${ }^{1}$ Department of Oral and Maxillofacial Surgery, \\ Yokohama City University Graduate School of Medicine, Yokohama, Japan; \\ ${ }^{2}$ Department of Radiology, Yokohama City University Graduate School of Medicine, Yokohama, Japan
}

\begin{abstract}
Aim: We aimed to retrospectively investigate the outcomes and pathological effects of retrograde superselective intra-arterial chemoradiotherapy (IACRT) combined with hyperthermia on metastatic lymph nodes of patients with oral squamous cell carcinoma. Patients and Methods: Patients with lymph node metastasis from oral cancer were treated with IACRT using cisplatin plus docetaxel combined with hyperthermia prior to surgical removal 8 weeks after completion of IACRT and hyperthermia. The locoregional control and overall survival rates were calculated using the Kaplan-Meier method. Results: A total of 35 patients received the combination therapy of whom 26 received it as definitive treatment and in the rest, it was administered as preoperative treatment. The 5-year locoregional control and overall survival rates were $95.6 \%$ and $80.2 \%$ in the definitive-treatment group, and $100 \%$ and $66.6 \%$ in the preoperative-treatment group, respectively. Conclusion: The combination therapy provided good outcomes in patients with lymph node metastases from advanced oral cancer.
\end{abstract}

Surgery is the most established modality for initial definitive treatment of oral cavity squamous cell carcinoma (OSCC) (1). However, extended surgery for patients with locally advanced OSCC may result in the loss of oral functions, including mastication, swallowing, and speech. In addition, locally advanced OSCC with skin invasion requires extensive resection

Correspondence to: Toshiyuki Koizumi, Department of Oral and Maxillofacial Surgery, Yokohama City University Graduate School of Medicine, 3-9 Fukuura, Kanazawa-ku, Yokohama, Kanagawa 236-0004, Japan. Tel.: +81 457872659, Fax: +81 457858438, e-mail: koizumi-tky@umin.ac.jp

Key Words: Oral squamous cell carcinoma, hyperthermia, retrograde superselective intra-arterial chemotherapy, concurrent radiotherapy, cervical lymph node metastasis. that leads to facial skin defects and causes significant cosmetic impairment and deterioration in the patient's quality of life. The ultimate goal of OSCC treatment is cancer control and organ preservation. Concurrent chemoradiotherapy (CRT) has improved the treatment outcome of locoregionally advanced head and neck cancer, such as laryngeal and pharyngeal carcinomas, particularly in terms of organ preservation (2). However, the treatment results of primary CRT remain unsatisfactory in patients with advanced OSCC. Surgery with or without postoperative radiotherapy results in better outcomes than definitive CRT $(3,4)$. We developed a retrograde superselective intra-arterial daily concurrent chemoradiotherapy (IACRT) regimen for advanced OSCC that allowed for the avoidance of primary tumor resection, enabled the preservation of oral functions, and improved outcomes (5-9).

The presence of cervical lymph node metastasis is among the most important prognostic factors for patients with OSCC. In the 2004-2013 National Cancer Database, the number of metastatic lymph nodes, extranodal extension, and lower neck involvement predicted the mortality rate in patients with OSCC (10). Our treatment strategy for patients with OSCC with advanced lymph node metastasis, particularly those with multiple lymph node metastases, is a combination of IACRT and hyperthermia for neck disease to control both the primary tumor and lymph node metastases. This combined treatment provided good pathological effects and high rates of locoregional control (LRC) and overall survival (OS) (11). Herein, we retrospectively analyzed the pathological effects of IACRT combined with hyperthermia on metastatic lymph nodes and prognosis of OSCC with lymph node metastases.

\section{Patients and Methods}

Patient selection. Patients were included in the analysis if they had an Eastern Cooperative Oncology Group (ECOG) performance status of 0 or 1; age over 20 years; a white blood cell count of at least 3,500 cells $/ \mathrm{mm}^{3}$; a platelet count of at least $100,000 / \mathrm{mm}^{3}$; a 
hemoglobin level of at least $9 \mathrm{~g} / \mathrm{dl}$; and no cerebral infarction or severe dysfunction of the liver, kidney, heart, and lung. The primary lesion and cervical lymph nodes were assessed via visual examination as well as via magnetic resonance imaging (MRI), ultrasonography, and enhanced computed tomography (CT) or positron-emission tomography (PET)-CT. Staging was according to the 2009 Union for International Cancer Control staging system (12). This study was performed in accordance with the ethical standards as laid down in the Declaration of Helsinki. The local Institutional Research Board approved this study (no. B141101002), and written informed consent was obtained from each patient.

Intra-arterial infusion procedure. Prior to catheterization, threedimensional CT angiography of the carotid artery was performed to identify the main tumor-feeding arteries and determine the morphology of the arteries originating from the external carotid artery. For retrograde superselective intra-arterial chemotherapy, catheters were inserted into the branches of the external carotid artery, namely, the lingual artery (LA), facial artery (FA), and maxillary artery, via the superficial temporal artery or occipital artery (OA) as previously described (13-16). If the lesion had extended beyond the median line, another catheter was inserted in the branches of the contralateral external carotid artery for bilateral arterial injection. After catheterization, the perfusion area of the anticancer agent was confirmed via digital subtraction angiography and angio-computed tomography performed by injecting $6 \mathrm{ml}$ of diluted contrast medium ( $3 \mathrm{ml}$ iopamidol and $3 \mathrm{ml}$ normal saline) for 5 seconds via a catheter to determine whether the anticancer agents delivered via arterial infusion permeated the entire tumor.

Treatment. The main goal of treatment for locally advanced OSCC is organ preservation. However, locally advanced mandibular gingival cancer or cancer of the floor of the mouth can easily extend to the mandibular bone marrow, which will make treating the primary tumor with IACRT difficult because of the small diameter of the inferior alveolar artery, a branch of the maxillary artery, which will lead to inadequate anticancer agent delivery. These patients were treated preoperatively with IACRT combined with hyperthermia prior to radical surgery, including primary resection and neck dissection (ND) with immediate reconstructive surgery (preoperative group). The other patients were treated with IACRT and hyperthermia to preserve organ function prior to ND (definitive group) (Figure 1).

Chemotherapy. The anticancer agent was infused through the intraarterial catheter during irradiation for 1 hour. The dose of docetaxel was $10 \mathrm{mg} / \mathrm{m}^{2} /$ week with a total of $60 \mathrm{mg} / \mathrm{m}^{2}$ for the definitive group and $40 \mathrm{mg} / \mathrm{m}^{2}$ for the preoperative group. The dose of cisplatin was $5 \mathrm{mg} / \mathrm{m}^{2} /$ day with a total of $150 \mathrm{mg} / \mathrm{m}^{2}$ for the definitive group and $100 \mathrm{mg} / \mathrm{m}^{2}$ for the preoperative group during the entire course of treatment. Sodium thiosulfate, a cisplatin-neutralizing agent, was also administered intravenously, $2 \mathrm{~g}$ total for each individual, immediately after arterial infusion of anticancer agent.

Radiotherapy. Radiotherapy (RT) was used concurrently with intraarterial chemotherapy. Three-dimensional conformal RT was performed at a dose of $4 \mathrm{MV}$ or $6 \mathrm{MV}$ at $2 \mathrm{~Gy} /$ fraction/day. The gross tumor volume (GTV) was defined as any visible evidence of disease on physical examination or on any imaging modality, including MRI, CT, or PET-CT. The clinical target volume (CTV) was defined as GTV plus 5-10 mm margin in all directions to cover microscopic disease. The CTV was expanded by $5 \mathrm{~mm}$ in all directions to create the planning target volume for setup uncertainty. The radiation field contained the primary site and neck levels I-IV on the ipsilateral side (N1) or neck levels I-V on the bilateral side (N2-3) as the CTV. In the preoperative group, the planned total dose delivered to the primary tumor and the metastatic lymph nodes was $40 \mathrm{~Gy} / 20$ fractions for each location. In the definitive group, the dose delivered was $40 \mathrm{~Gy} / 20$ fractions for the primary tumor site and the neck, plus additional irradiation for both sites. The planned total dose delivered to the primary tumor and the metastatic lymph nodes was $60 \mathrm{~Gy} / 30$ fractions for each locale. The dose delivered to the spinal cord ranged from $40 \mathrm{~Gy}$ to $45 \mathrm{~Gy}$.

Hyperthermia for cervical lymph node metastases. The selection criteria to add hyperthermia to IACRT were patients with multiple lymph node metastases, huge lymph nodes such as N3 disease, or a single neck disease with remarkable tendency to grow. Hyperthermia was delivered via a radiofrequency current thermotherapy instrument (8 MHz, radiofrequency output range of $60-1500 \mathrm{~W}$; Thermotron RF-8; Yamamoto Vinita Co Ltd, Osaka, Japan), and was performed within an hour after completion of IACRT. The procedure was performed once or twice weekly for 50 minutes at an output that raised the cervical skin surface temperature to $42-43.5^{\circ} \mathrm{C}$ for cervical lymph node metastases (Figure 1).

Evaluation and surgery. All patients were evaluated 4 weeks after completion of IACRT combined with hyperthermia via enhanced CT, MRI, or PET-CT. In the definitive group, tissue biopsy of the primary lesion was also performed 5-6 weeks after the treatment to pathologically evaluate the clinical response. For patients whose pathological response in the primary tumor was confirmed to be complete response (CR), the planned ND was performed and the pathological response of the metastatic lymph node was evaluated 8 weeks after the entire treatment course (Figure 1A). If residual tumor was present at the primary site after treatment, a salvage operation was performed. ND was performed if clinical evidence of late cervical lymph node metastases was seen during follow-up. In the preoperative group, radical surgery including primary resection and ND with immediate reconstructive surgery was performed 8 weeks after completion of IACRT combined with hyperthermia (Figure 1B). The pathological response of the primary tumor and metastatic lymph nodes were evaluated using surgical specimens.

Toxicity assessment. Treatment-related toxicities were analyzed in accordance with the Common Terminology Criteria for Adverse Events, version 4.0 (17). The evaluation included blood cell counts, oral mucositis, radiation dermatitis, renal dysfunction, and burns from the beginning of the combination therapy to 4 weeks after completion of treatment, since acute toxicities and dry mouth and osteonecrosis of the jaw are late toxicities.

Statistical analysis. LRC and OS rates were calculated using the Kaplan-Meier method. Events were measured from the start of treatment. All analyses were performed using SPSS version 20 (IBM SPSS Inc., Armonk, NY, USA).

\section{Results}

Study population. Between September 2007 and January 2015, a total of 807 patients with head and neck malignancies were referred to our Institution. Among them, 41 patients with lymph node metastases from OSCC were treated using IACRT 


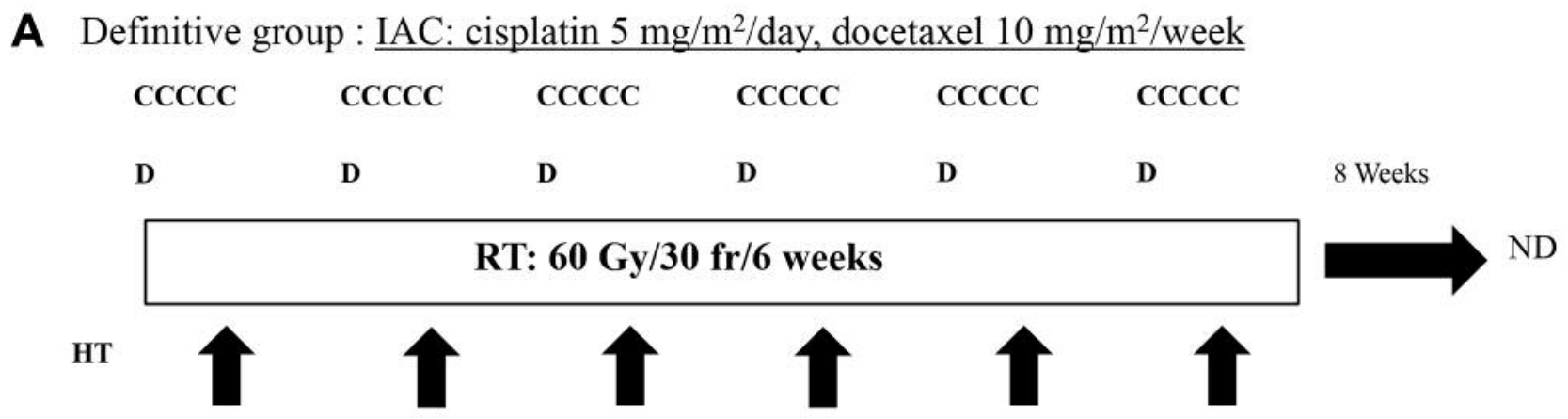

B Pre-operative group : IAC: cisplatin $5 \mathrm{mg} / \mathrm{m}^{2} /$ day, docetaxel $10 \mathrm{mg} / \mathrm{m}^{2} /$ week

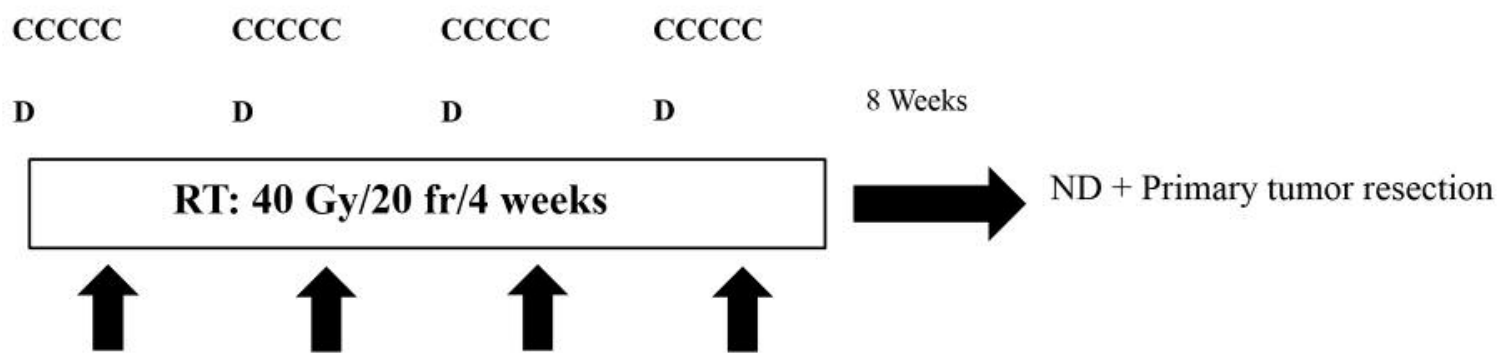

Figure 1. Treatment schedule for intra-arterial infusion chemoradiotherapy combined with hyperthermia. A: In the definitive group, treatment comprised radiotherapy (total $60 \mathrm{~Gy}$ ), superselective intra-arterial chemotherapy [total doses: $150 \mathrm{mg} / \mathrm{m}^{2}$ cisplatin $(C), 60 \mathrm{mg} / \mathrm{m}^{2}$ docetaxel (D)], and hyperthermia. B: In the preoperative group, treatment comprised radiotherapy (total 40 Gy), superselective intra-arterial chemotherapy [total doses: $100 \mathrm{mg} / \mathrm{m}^{2}$ cisplatin; $40 \mathrm{mg} / \mathrm{m}^{2}$ docetaxel], and hyperthermia. Fr: Fraction; HT: hyperthermia; IAC: intra-arterial infusion chemotherapy; $N D$ : neck dissection; $R T$ : radiotherapy.

combined with hyperthermia. Six patients were excluded due to the presence of distant metastases $(n=3)$ detected on image examinations 4 weeks after completion of treatment, or refusal of surgery $(n=3)$. Thus, 35 patients were evaluated for pathological responses and clinical outcomes. The median follow-up for patients, overall, was 60 months (range $=5-124$ months). The median age of patients was 57 years (range $=35$ 81 years). Of the 35 patients, five, 22 , and eight had stage III, IVA, and IVB disease, respectively (Table I).

Intra-arterial chemoradiotherapy and hyperthermia. Twentysix patients received IACRT (total doses: radiation: 50-70 Gy; docetaxel: $50-70 \mathrm{mg} / \mathrm{m}^{2}$; cisplatin: $125-175 \mathrm{mg} / \mathrm{m}^{2}$ ) combined with hyperthermia as a definitive treatment, while in the other nine it was administered as preoperative treatment (total doses: radiation: 40-50 Gy; docetaxel: 40-50 $\mathrm{mg} / \mathrm{m}^{2}$; cisplatin: $100-125 \mathrm{mg} / \mathrm{m}^{2}$ ). A median of five hyperthermia treatment sessions were performed (range $=3-8$ sessions) for the definitive group and four (range $=3-8$ sessions) for the preoperative group (Table I).

Treatment result and pathological response. After completion of IACRT combined with hyperthermia, all 26 patients (100\%) in the definitive group achieved clinical CR in the primary tumor. A pathological CR of the metastatic lymph nodes was achieved in 17 patients $(65 \%)$ in the definitive group, and six patients $(67 \%)$ in the preoperative group (Table II). During follow-up, two and one patients were found to have locoregional recurrence in the definitive and preoperative groups, respectively. A total of nine patients died from distant metastasis $(n=7)$, pneumonia $(n=1)$, and encephalopathy $(n=1)$.

In the definitive group, the 5-year LRC and OS rates were $95.6 \%$ and $80.2 \%$, respectively (Figure $2 \mathrm{~A}$ ), while in the preoperative group, these rates were $100 \%$ and $66.6 \%$, respectively (Figure 2B).

Treatment-related toxicities. In the definitive group, grade 3 toxicities included mucositis in 25 patients $(96 \%)$, dermatitis in eight $(31 \%)$, neutropenia in seven $(27 \%)$, anemia in four $(15 \%)$, and thrombocytopenia in one $(4 \%)$ patient. Late toxicity consisting of grade 3 osteonecrosis of the jaw occurred in one patient (4\%) (Table III). In the preoperative group, grade 3 or 4 anemia occurred in three patients (33\%). Grade 3 toxicities included mucositis in eight patients $(89 \%)$ and neutropenia in two (22\%) (Table III). 
Table I. Patient characteristics and treatment details.

\begin{tabular}{|c|c|c|c|}
\hline \multirow[b]{2}{*}{ Characteristic } & \multirow[b]{2}{*}{ Total } & \multicolumn{2}{|c|}{ Treatment group } \\
\hline & & $\begin{array}{l}\text { Definitive } \\
\text { group }\end{array}$ & $\begin{array}{c}\text { Pre-operative } \\
\text { group }\end{array}$ \\
\hline No. of patients & 35 & 26 & 9 \\
\hline Median age, years (range) & $57(35-81)$ & $55(35-81)$ & $61(55-71)$ \\
\hline \multicolumn{4}{|l|}{ Gender, $\mathrm{n}$} \\
\hline Male & 23 & 16 & 7 \\
\hline Female & 12 & 10 & 2 \\
\hline \multicolumn{4}{|l|}{ ECOG PS, n } \\
\hline 0 & 30 & 23 & 7 \\
\hline 1 & 5 & 4 & 1 \\
\hline \multicolumn{4}{|l|}{ Primary tumor site, $\mathrm{n}$} \\
\hline Tongue & 19 & 18 & 1 \\
\hline Lower gingiva & 6 & 1 & 5 \\
\hline Upper gingiva & 6 & 6 & 0 \\
\hline Floor of mouth & 3 & 0 & 3 \\
\hline Buccal mucosa & 1 & 1 & 0 \\
\hline \multicolumn{4}{|l|}{$\mathrm{T}$ Classification, $\mathrm{n}$} \\
\hline $\mathrm{T} 2$ & 8 & 7 & 1 \\
\hline $\mathrm{T} 3$ & 13 & 12 & 1 \\
\hline $\mathrm{T} 4 \mathrm{a}$ & 12 & 6 & 6 \\
\hline $\mathrm{T} 4 \mathrm{~b}$ & 2 & 1 & 1 \\
\hline \multicolumn{4}{|l|}{$\mathrm{N}$ Classification, $\mathrm{n}$} \\
\hline N1 & 8 & 8 & 0 \\
\hline $\mathrm{N} 2 \mathrm{~b}$ & 15 & 13 & 2 \\
\hline $\mathrm{N} 2 \mathrm{c}$ & 6 & 3 & 3 \\
\hline $\mathrm{N} 3$ & 6 & 2 & 4 \\
\hline \multicolumn{4}{|l|}{ Stage, $\mathrm{n}$} \\
\hline III & 5 & 5 & 0 \\
\hline IVA/IVB & $22 / 8$ & $18 / 3$ & $4 / 5$ \\
\hline \multicolumn{4}{|l|}{ Total dose of RT, Gy } \\
\hline Median (range) & $60(40-70)$ & $60(50-70)$ & $40(40-50)$ \\
\hline \multicolumn{4}{|c|}{ No. of hyperthermia treatments } \\
\hline Median (range) & $4(3-8)$ & $5(3-8)$ & $4(3-8)$ \\
\hline
\end{tabular}

ECOG PS: Eastern Cooperative Oncology Group performance status; RT: radiotherapy.

None of the patients experienced renal dysfunction, burn, or dry mouth of grade 3 or higher. No treatment-related deaths occurred during the treatment and follow-up periods.

\section{Discussion}

Surgery with or without postoperative CRT or radiotherapy is a standard treatment for patients with advanced OSCC. In the present study, the pathological effect of combined IACRT and hyperthermia treatment on metastatic lymph nodes, and prognosis of OSCC with lymph node metastases were analyzed. We observed pathological CR in $66 \%$ of patients with metastatic lymph nodes, and the 5-year LRC and OS rates were $93.3 \%$ and $76.7 \%$, respectively. The LRC rate among patients with cervical lymph node metastases from OSCC was excellent. The results of our study showed the

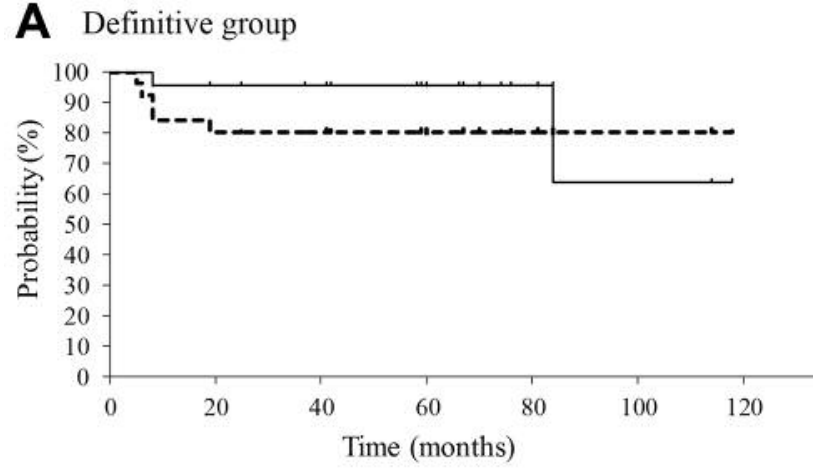

B Preoperative group

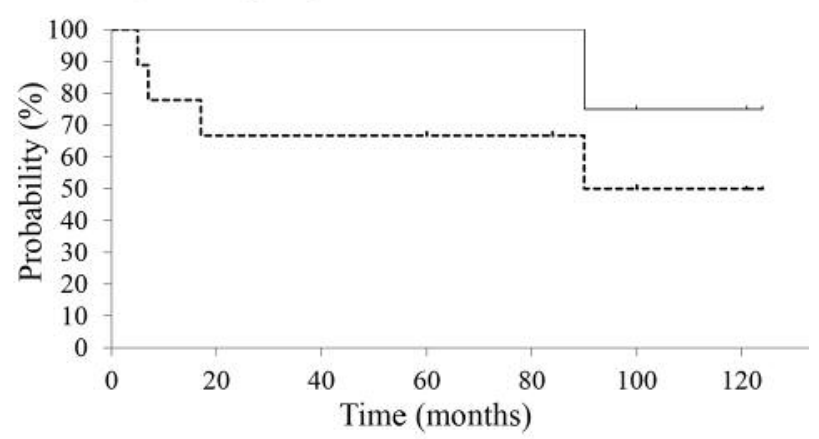

Figure 2. Locoregional control (LRC) and overall survival (OS) rates calculated using the Kaplan-Meier method. A: For the definitively treated group, the 5-year LRC and OS rates were $95.6 \%$ and $80.2 \%$, respectively. B: For the preoperatively treated group, the 5-year LRC and $\mathrm{OS}$ rates were $100 \%$ and $66.6 \%$, respectively.

benefit of combining IACRT and hyperthermia in patients with cervical lymph node metastases of OSCC. Hyperthermia itself has an anticancer effect (18). Moreover, hyperthermia offers complementary and additive effect for radiotherapy and chemotherapy and has relatively mild adverse events.

In a study of 850 surgically treated patients with OSCC, researchers at Tata Memorial Centre in India reported a 5year OS rate of $70.4 \%$ for the entire study group and $68.4 \%$ for those with stage III and IV disease (19). Moreover, cervical lymph node metastasis strongly influences prognosis in patients with OSCC. The number of positive lymph nodes was found to significantly affect prognosis among those with $\mathrm{N} 2 \mathrm{~b}$ and $\mathrm{N} 2 \mathrm{c}$ OSCC in data from the National Cancer Database (10). An in vivo study reported that radio-resistant cells such as cells growing in hypoxic lower-pH environment are thermosensitive (20). Hyperthermia has a thermal sensitizer effect for RT and has been reported to have additive or synergistic effects with several chemotherapeutic agents administered for therapy of various solid tumors (21).

In a systematic review, Datta et al. evaluated and compared the outcomes of RT plus hyperthermia to those of 
Table II. Pathological responses of primary tumor and metastatic lymph nodes in the definitive $(n=26)$ preoperative $(n=9)$ treatment groups.

\begin{tabular}{|c|c|c|c|c|}
\hline & \multicolumn{2}{|c|}{ Definitive group, n (\%) } & \multicolumn{2}{|c|}{ Preoperative group, n (\%) } \\
\hline & Pathological CR & Residual tumor & Pathological CR & Residual tumor \\
\hline Primary tumor & $26(100)$ & $0(0)$ & $5(56)$ & $4(44)$ \\
\hline Metastatic lymph nodes & $17(65)$ & $9(35)$ & $6(67)$ & $3(33)$ \\
\hline
\end{tabular}

CR: Complete response.

Table III. Treatment-related toxicities in the definitive $(n=26)$ preoperative $(n=9)$ treatment groups. No grade 5 toxicities were found in either group.

\begin{tabular}{|c|c|c|c|c|c|c|c|c|c|}
\hline \multirow[b]{2}{*}{ Toxicity } & & \multicolumn{2}{|c|}{ Grade $1 \mathrm{n}(\%)$} & \multicolumn{2}{|c|}{ Grade 2 n $(\%)$} & \multicolumn{2}{|c|}{ Grade 3 n (\%) } & \multicolumn{2}{|c|}{ Grade 4 n (\%) } \\
\hline & & Definitive & Preoperative & Definitive & Preoperative & Definitive & Preoperative & Definitive & Preoperative \\
\hline \multirow[t]{7}{*}{ Acute } & Neutropenia & $12(46)$ & $3(33)$ & $7(27)$ & $4(45)$ & $7(27)$ & $2(22)$ & 0 & 0 \\
\hline & Thrombocytopenia & $23(88)$ & $7(78)$ & $2(8)$ & $2(22)$ & $1(4)$ & 0 & 0 & 0 \\
\hline & Anemia & $9(35)$ & $4(45)$ & $13(50)$ & $2(22)$ & $4(15)$ & $2(22)$ & 0 & $1(11)$ \\
\hline & Oral mucositis & 0 & 0 & $1(4)$ & $1(11)$ & $25(96)$ & $8(89)$ & 0 & 0 \\
\hline & Dermatitis & $3(12)$ & $3(33)$ & $14(54)$ & $6(67)$ & $8(31)$ & 0 & 0 & 0 \\
\hline & Renal dysfunction & $1(4)$ & $1(11)$ & $2(8)$ & $2(22)$ & 0 & 0 & 0 & 0 \\
\hline & Burn & $17(65)$ & $6(67)$ & $9(35)$ & $3(33)$ & 0 & 0 & 0 & 0 \\
\hline \multirow[t]{2}{*}{ Late } & Dry mouth & $12(46)$ & $2(22)$ & 0 & $1(11)$ & 0 & 0 & 0 & 0 \\
\hline & Osteonecrosis & 0 & 0 & $2(8)$ & $1(11)$ & $1(4)$ & 0 & 0 & 0 \\
\hline
\end{tabular}

Table IV. Summary of treatment characteristics and outcomes of head and neck cancer studies (chemoradiation with or without hyperthermia).

\begin{tabular}{|c|c|c|c|c|c|c|c|c|}
\hline \multirow[b]{2}{*}{$\begin{array}{l}\text { Author (year) } \\
\text { (Ref) }\end{array}$} & \multirow[b]{2}{*}{ Type of study } & \multirow[b]{2}{*}{$\begin{array}{l}\text { Stage/site } \\
\text { (n) }\end{array}$} & \multirow[b]{2}{*}{ RT dose } & \multirow[b]{2}{*}{$\begin{array}{c}\text { HT } \\
\text { sessions }\end{array}$} & \multicolumn{2}{|c|}{$\mathrm{CRT}+\mathrm{HT}$} & \multicolumn{2}{|r|}{ CRT } \\
\hline & & & & & $\begin{array}{l}\mathrm{CR} / \text { total } \mathrm{CR}, \\
\text { rate }(\%)\end{array}$ & Survival & $\begin{array}{l}\mathrm{CR} / \text { total } \mathrm{CR}, \\
\text { rate }(\%)\end{array}$ & Survival \\
\hline $\begin{array}{l}\text { Svetitsky } \\
\text { (1990) (26) }\end{array}$ & Randomized & $\begin{array}{c}\text { Recurrent/ } \\
\text { laryngeal (54) }\end{array}$ & $30 \mathrm{~Gy}$ & 9 & $8 / 26(30.8 \%)$ & $\begin{array}{c}\text { 2-Year OS }=75 \% \\
3 \text {-Year OS=30.8\% }\end{array}$ & $0 / 28(0 \%)$ & $\begin{array}{l}\text { 2-Year OS }=7 \% \\
\text { 3-Year OS }=0 \%\end{array}$ \\
\hline $\begin{array}{l}\text { Huilgol et al. } \\
\text { (2010) (27) }\end{array}$ & Retrospective & $\begin{array}{l}\text { Stage III, IV/ } \\
\text { HNC (38) }\end{array}$ & $70 \mathrm{~Gy}$ & $4-7$ & $29 / 38(76.2 \%)$ & $\begin{array}{l}1-\text { Year OS }=75.7 \% \\
2-\text { Year OS=63.1\% }\end{array}$ & & \\
\hline $\begin{array}{l}\text { Mitsudo et al. } \\
\text { (2012) (11) }\end{array}$ & Retrospective & $\begin{array}{l}\text { T2-T4N3/ } \\
\text { Oral (9) }\end{array}$ & 40-60 Gy & $2-8$ & $\begin{array}{l}5 / 7(71.4 \%) \\
\text { (IACRT) }\end{array}$ & $\begin{array}{c}5-\text { Year OS=51\% } \\
(5-\text { Year LRC=88\%) }\end{array}$ & & \\
\hline $\begin{array}{l}\text { Kang et al. } \\
\text { (2013) (28) }\end{array}$ & Randomized & $\begin{array}{l}\mathrm{T} 1-4 \mathrm{~N} 2-3 \mathrm{M} 0 / \\
\mathrm{NP}(154)\end{array}$ & 70-78 Gy & $3-14$ & $62 / 76(81.6 \%)$ & $\begin{array}{l}\text { 5-Year OS=68.4\% } \\
(5-\text { Year LC }=96.1 \%)\end{array}$ & $49 / 78(62.8 \%)$ & $\begin{array}{l}\text { 5-Year OS=50.0\% } \\
(5-\text { Year LC }=76.9 \%)\end{array}$ \\
\hline $\begin{array}{l}\text { Kouloulias et al. } \\
\text { (2014) (29) }\end{array}$ & Retrospective & $\begin{array}{c}\text { T3N0/ } \\
\text { Laryngeal (25) }\end{array}$ & 70 Gy & 6 & $23 / 25(92 \%)$ & & & \\
\hline
\end{tabular}

HNC: Head and neck cancer; CRT: chemoradiotherapy; IACRT: intra-arterial chemoradiotherapy; CR: complete response; OS: overall survival; LRC: locoregional control; LC: local control; NP: nasopharyngeal.

RT alone for head and neck cancer. The overall CR for those treated with RT alone and RT plus hyperthermia was $39.6 \%$ $(92 / 232 ; \quad$ range $=31.3 \%-46.9 \%)$ and $62.5 \% \quad(137 / 219$; range $=33.9-83.3 \%$ ), respectively. The rate of CR in RT combined with hyperthermia was higher than that for RT alone in head and neck cancer, with no significant additional acute and late morbidities in 451 clinical cases from six studies (22). This systematic review and meta-analysis provided level I evidence on the efficacy of RT combined with hyperthermia over radiotherapy alone.

Concurrent CRT with platinum-based regimens is currently among the standard treatment modalities for definitive treatment of locoregionally advanced SCC of the head and neck (23-25). Some reports of head and neck cancer in which definitive CRT, 

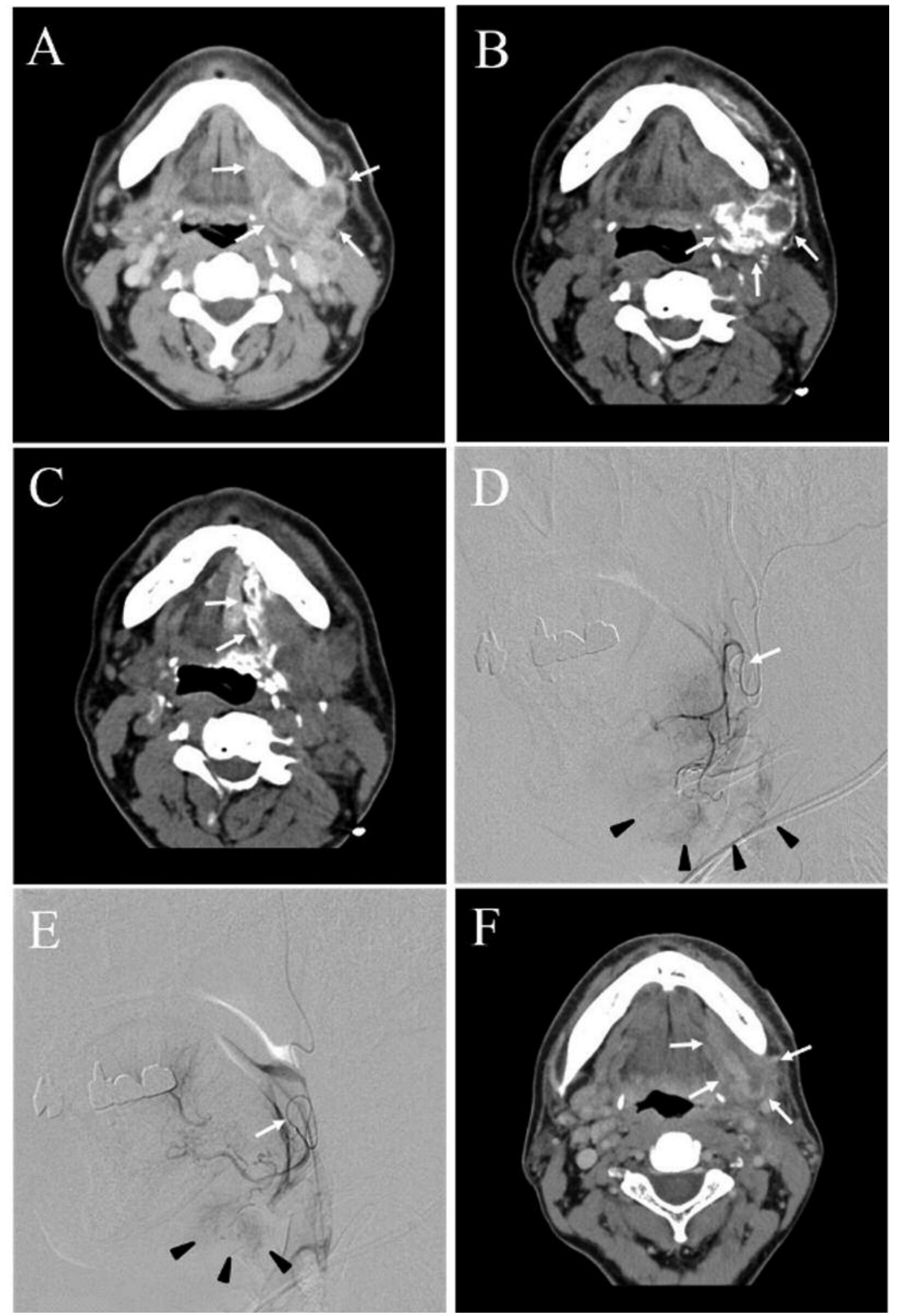

Figure 3. Squamous cell carcinoma of the left side of the tongue (T3N3M0). A: Enhanced computed tomographic findings of N3 neck disease before treatment (arrows). B, C: Axial view of angio-CT images after catheterization. Tumor staining of the N3 can be seen from the left facial artery (B, arrows) and the lingual artery (C, arrows) with the use of contrast medium. D, E: Lateral view of digital subtraction angiography images. Two catheters were superselectively inserted into the left facial (D, arrow) and the left lingual arteries (E, arrow). Tumor staining of the N3 was observed with contrast medium (arrow heads). F: The clinical response of the N3 was partial response after intra-arterial chemoradiotherapy and hyperthermia (arrows). 
with or without hyperthermia, was the therapeutic modality are summarized in Table IV. Two out of the five trials were randomized, and three were nonrandomized studies (11, 26-29). Kang et al. in their prospective, randomized, multicenter study for patients with nasopharyngeal carcinoma reported that the addition of hyperthermia to CRT improved local control and OS compared with CRT alone (28).

Intra-arterial infusion of anticancer agents into tumorfeeding arteries is an effective method to direct higher doses of anticancer agents to tumors, with lower toxicity than systemic chemotherapy. Lee et al. first reported the use of superselective intra-arterial chemotherapy for head and neck cancer via the femoral artery using the Seldinger method (30). Robbins et al. reported the use of rapid weekly superselective intra-arterial infusion of supradose cisplatin combined with sodium thiosulfate for cisplatin neutralization (31). The transfemoral approach enables simultaneous infusion of anticancer agents into several target arteries. However, it can sometimes cause serious adverse events such as a cranial nerve disorder (32). We developed a retrograde intra-arterial infusion method via superficial temporal artery or occipital artery, which is feasible for RT and daily concurrent chemotherapy. The superficial temporal approach is technically simple and probably the most secure method of inserting a catheter into the target artery with very low risk of cerebrovascular disorders. In addition, due to the relatively low daily dose of the anticancer agent administered, this method can be used in elderly patients (8). Intra-arterial chemotherapy sometimes has a therapeutic effect for cervical lymph node metastases. In our previous study, we investigated the perfusion of anticancer agent to the neck through an intra-arterial catheter and found that neck levels IA, ipsilateral IB and IIA, and contralateral IB were perfused from LA and FA (7). Perfusions to the site of $\mathrm{N} 3$ cervical lymph node metastasis from the intra-arterial catheters inserted into the LA and FA is shown in Figure 3. A large pathological effect on metastatic lymph nodes can be expected when an anticancer agent is administered to the neck disease through intra-arterial infusion.

In terms of acute adverse events, $94 \%$ of the patients experienced grade 3 oral mucositis during treatment. Thirty patients $(86 \%)$ in the present study depended on percutaneous endoscopic gastrostomy or a nasogastric tube for feeding during IACRT combined with hyperthermia. However, the feeding tube was removed within 4 to 24 weeks after combination therapy, because patients with severe oral mucositis recovered to the extent that oral intake was possible. Severe renal dysfunction was not observed during treatment. This is because the total dose of cisplatin was relatively low $\left(150 \mathrm{mg} / \mathrm{mm}^{2}\right.$ for definitive treatment and $100 \mathrm{mg} / \mathrm{mm}^{2}$ for preoperative treatment) compared with the amount administered in general systemic chemotherapy. Previous studies reported that the incidence of osteonecrosis of the jaw post RT ranges from $1.2 \%$ to $11 \%(3,33-37)$. The incidence of osteonecrosis in the present study was a little higher compared to that in previously published data, with grade 2 or 3 being observed in $11 \%$ of the patients. The onset of osteonecrosis post RT depended primarily on the patient's oral hygiene status before treatment and during follow-up. Therefore, dental screening of patients with OSCC before radiotherapy as well as long-term follow-up is necessary.

In conclusion, the present study showed good treatment outcomes from IACRT combined with hyperthermia not only in terms of LRC and OS rates, but also pathological effect in both the definitive and preoperative groups. Treatmentrelated toxicities were also manageable. The enhanced therapeutic effect from the use of IACRT combined with hyperthermia can improve prognosis in patients with lymph node metastasis from advanced OSCC. However, we do not have directly comparable data to prove the synergistic effect of IACRT plus hyperthermia in the treatment of patients with OSCC. Future prospective trials should be performed to evaluate the additive effect of hyperthermia plus IACRT compared to IACRT alone for the management of patients with OSCC and cervical lymph node metastases.

\section{Conflicts of Interest}

The Authors declare that they have no conflicts of interest associated with this study.

\section{Authors' Contributions}

Tomoyo Nozato designed the study, and wrote the initial draft of the manuscript. Toshiyuki Koizumi designed the study, contributed to analysis and interpretation of data, and assisted in the preparation of the manuscript. All other authors have contributed to data collection and interpretation, and critically reviewed the manuscript. All Authors approved the final version of the manuscript, and agree to be accountable for all aspects of the work in ensuring that questions related to the accuracy or integrity of any part of the work are appropriately investigated and resolved.

\section{Acknowledgements}

This work was supported in part by the JSPS KAKENHI (Grant Number JP26463053) to T.K. and 16K11730 to K.M.

\section{References}

1 Shah JP and Gil Z: Current concepts in management of oral cancer-surgery. Oral Oncol 45(4-5): 394-401, 2009. PMID: 18674952, DOI: 10.1016/j.oraloncology. 2008.05.017

2 Salama JK, Seiwert TY and Vokes EE: Chemoradiotherapy for locally advanced head and neck cancer. J Clin Oncol 25(26): 41184126, 2007. PMID: 17827462, DOI: 10.1200/JCO.2007. 12.2697

3 Crombie AK, Farah C, Tripcony L, Dickie G and Batstone MD: Primary chemoradiotherapy for oral cavity squamous cell carcinoma. Oral Oncol 48(10): 1014-1018, 2012. PMID: 22516377, DOI: 10.1016/j.oraloncology.2012.03.027 
4 Gore SM, Crombie AK, Batstone MD and Clark JR: Concurrent chemoradiotherapy compared with surgery and adjuvant radiotherapy for oral cavity squamous cell carcinoma. Head Neck 37(4): 518-523, 2015. PMID: 24532246, DOI: 10.1002/ hed.23626

5 Mitsudo K, Shigetomi T, Fujimoto Y, Nishiguchi H, yamamoto $\mathrm{N}$, Furue H, Ueda M, Itoh Y, Fuwa N and Tohnai I: Organ preservation with daily concurrent chemoradiotherapy using superselective intra-arterial infusion via a superficial temporal artery for T3 and T4 head and neck cancer. Int J Radiat Oncol Biol Phys 79(5): 1428-1435, 2011. PMID: 20605340, DOI: 10.1016/j.ijrobp.2010.01.011

6 Mitsudo K, Koizumi T, Iida M, Iwai T, Nakashima H, Oguri S, Kioi M, Hirota M, Koike I, Hata M and Tohnai I: Retrograde superselective intra-arterial chemotherapy and daily concurrent radiotherapy for stage III and IV oral cancer: Analysis of therapeutic results in 112 cases. Radiother Oncol 111(2): 306-310, 2014. PMID: 24746571, DOI: 10.1016/j.radonc. 2014.03.005

7 Minamiyama S, Mitsudo K, Hayashi Y, Iida M, Iwai T, Nakashima H, Oguri S, Ozawa T, Koizumi T, Hirota M, Kioi M and Tohnai I: Retrograde superselective intra-arterial chemotherapy and daily concurrent radiotherapy for T2-4N0 tongue cancer: Control of occult neck metastasis. Oral Surg Oral Med Oral Pathol Oral Radiol 124(1): 16-23, 2017. PMID: 28434836, DOI: 10.1016/j.oooo.2017.02.004

8 Hayashi Y, Mitsudo K, Sakuma K, Iida M, Iwai T, Nakashima H, Okamoto Y, Koizumi T, Oguri S, Hirota M, Kioi M, Koike I, Hata $\mathrm{M}$ and Tohnai I: Clinical outcomes of retrograde intraarterial chemotherapy concurrent with radiotherapy for elderly oral squamous cell carcinoma patients aged over 80 years old. Radiat Oncol 12(1): 112, 2017. PMID: 28673362, DOI: 10.1186/ s13014-017-0847-3

9 Mitsudo K, Hayashi Y, Minamiyama S, Ohashi N, Iida M, Iwai T, Oguri S, Koizumi T, Kioi M, Hirota M, Koike I, Hata M and Tohnai I: Chemoradiotherapy using retrograde superselective intra-arterial infusion for tongue cancer: Analysis of therapeutic results in 118 cases. Oral Oncol 79: 71-77, 2018. PMID: 29598953, DOI: 10.1016/j.oraloncology.2018.02.002

10 Ho AS, Kim S, Tighiouart M, Gudino C, Mita A, Scher KS, Laury A, Prasad R, Shiao SL, Van Eyk JE and Zumsteg ZS: Metastatic lymph node burden and survival in oral cavity cancer. J Clin Oncol 35(31): 3601-3609, 2017. PMID: 28880746, DOI: 10.1200/JCO.2016.71.1176

11 Mitsudo K, Koizumi T, Iida M, Iwai T, Oguri S, Yamamoto N, Itoh Y, Kioi M, Hirota M and Tohnai I: Thermochemoradiation therapy using superselective intra-arterial infusion via superficial temporal and occipital arteries for oral cancer with $\mathrm{N} 3$ cervical lymph node metastases. Int J Radiat Oncol Biol Phys 83(5): e639645, 2012. PMID: 22543212, DOI: 10.1016/j.ijrobp. 2012.02.057

12 Sobin LH, Gospodarowicz MK and Wittekind C: TNM Classification of Malignant Tumors, 7th ed. Hoboken, WileyBlackwell Publ Corp., pp. 25-29, 2011.

13 Shimizu T, Sakakura Y, Hattori T, Yamaguchi N, Kubo M and Sakakura K: Superselective intraarterial chemotherapy in combination with irradiation: preliminary report. Am J Otolaryngol 11(2): 131-136, 1990. PMID: 2343996, DOI: 10.1016/0196-0709(90)90009-K

14 Tohnai I, Fuwa N, Hayashi Y, Kaneko R, Tomaru Y, Hibino Y and Ueda M: New superselective intra-arterial infusion via superficial temporal artery for cancer of the tongue and tumour tissue platinum concentration after carboplatin (CBDCA) infusion. Oral Oncol 34(5): 387-390, 1998. PMID: 9861346, DOI: $10.1016 / \mathrm{S} 1368-8375(98) 00018-9$

15 Fuwa N, Ito Y, Matsumoto A, Kamata M, Kodaira T, Furutani K, Sasaoka M, Kimura Y and Morita K: A combination therapy of continuous superselective intraarterial carboplatin infusion and radiation therapy for locally advanced head and neck carcinoma. Phase 1 study. Cancer 89(10): 2099-2105, 2000. PMID: 11066051, DOI: 10.1002/1097-0142(20001115) 89:103.0.CO;2-4

16 Iwai T, Fuwa N, Hirota M, Mitsudo K and Tohnai I: Secure surgical method for catheter placement via the occipital artery to achieve retrograde superselective intra-arterial chemotherapy for advanced oral cancer: Alternative to approach via the superficial temporal artery. Indian J Otolaryngol Head Neck Surg 66(2): 205207, 2014. PMID: 24822164, DOI: 10.1007/s 12070-012-0501-1

17 Common Terminology Criteria for Adverse Events: Version 4.0. Bethesda, National Cancer Institute, 2009. Available at https://evs.nci.nih.gov/ftp1/CTCAE/CTCAE_4.03/Archive/CTC AE_4.0_2009-05-29_QuickReference_8.5x11.pdf

18 Dewey WC, Hopwood LE, Sapareto SA and Gerweck LE: Cellular responses to combinations of hyperthermia and radiation. Radiology 123(2): 463-474, 1977. PMID: 322205, DOI: $10.1148 / 123.2 .463$

19 Nair D, Singhvi H, Mair M, Qayyumi B, Deshmukh A, Pantvaidya G, Nair S, Chaturvedi P, Laskar SG, Prabhash K and DCruz A: Outcomes of surgically treated oral cancer patients at a tertiary cancer center in India. Indian J Cancer 54(4): 616-620, 2017. PMID: 30082545, DOI: 10.4103/ijc.IJC_445_17

20 Hahn GM and Shiu EC: Adaptation to low pH modifies thermal and thermo-chemical responses of mammalian cells. Int $\mathrm{J}$ Hyperthermia 2(4): 379-387, 1986. PMID: 2433369, DOI: $10.3109 / 02656738609004968$

21 Datta NR, Ordóñez SG, Gaipl US, Paulides MM, Crezee H, Gellermann J, Marder D, Puric E and Bodis S: Local hyperthermia combined with radiotherapy and-/or chemotherapy: Recent advances and promises for the future. Cancer Treat Rev 41(9): 742753, 2015. PMID: 26051911, DOI: 10.1016/j.ctrv.2015.05.009

22 Datta NR, Rogers S, Ordóñez SG, Puric E and Bodis S: Hyperthermia and radiotherapy in the management of head and neck cancers: A systematic review and meta-analysis. Int J Hyperthermia 32(1): 31-40, 2016. PMID: 26928474, DOI: 10.3109/02656736.2015.1099746

23 Wendt TG, Grabenbauer GG, Rödel CM, Thiel HJ, Aydin H, Rohloff R, Wustrow TP, Iro H, Popella C and Schalhorn A: Simultaneous radiochemotherapy versus radiotherapy alone in advanced head and neck cancer: A randomized multicenter study. J Clin Oncol 16(4): 1318-1324, 1998. PMID: 9552032, DOI: 10.1200/JCO.1998.16.4.1318

24 Pignon JP, Bourhis J, Domenge C, Designé L: Chemotherapy added to locoregional treatment for head and neck squamous-cell carcinoma: Three meta-analyses of updated individual data. MACH-NC Collaborative Group. Meta-analysis of chemotherapy on head and neck cancer. Lancet 355(9208): 949-955, 2000. PMID: 10768432, DOI: 10.1016/S0140-6736(00)90011-4

25 Adelstein DJ, Li Y, Adams GL, Wagner H Jr, Kish JA, Ensley JF, Schuller DE and Forastiere AA: An Intergroup phase III comparison of standard radiation therapy and two schedules of concurrent chemoradiotherapy in patients with unresectable squamous cell head and neck cancer. J Clin Oncol 21(1): 92-98, 2003. PMID: 12506176, DOI: 10.1200/JCO.2003.01.008 
26 Svetitsky PV: Effect of microwave and ionizing radiation in patients with recurrent laryngeal carcinoma. J Laryngol Otol 104(9): 704-705, 1990. PMID: 2230578.

27 Huilgol NG, Gupta S and Dixit R: Chemoradiation with hyperthermia in the treatment of head and neck cancer. Int $\mathrm{J}$ Hyperthermia 26(1): 21-25, 2010. PMID: 20100049, DOI: $10.3109 / 02656730903418283$

28 Kang M, Liu WQ, Qin YT, Wei ZX and Wang RS: Long-term efficacy of microwave hyperthermia combined with chemoradiotherapy in treatment of nasopharyngeal carcinoma with cervical lymph node metastases. Asian Pac J Cancer Prev 14(12): 7395-7400, 2013. PMID: 24460309, DOI: 10.7314/ APJCP.2013.14.12.7395

29 Kouloulias V, Triantopoulou S, Vrouvas J, Gennatas K, Ouzounoglou N, Kouvaris J, Karaiskos P, Aggelakis P, Antypas C, Zygogianni A, Papavasiliou K, Platoni K and Kelekis N: Combined chemoradiotherapy with local microwave hyperthermia for treatment of T3N0 laryngeal carcinoma: a retrospective study with long-term follow-up. Acta Otorhinolaryngol Ital 34(3): 167173, 2014. PMID: 24882925.

30 Lee YY, Wallace S, Dimery I and Goepfert H: Intraarterial chemotherapy of head and neck tumors. Am J Neuroradiol 7(2): 343-348, 1986. PMID: 3082167.

31 Robbins KT, Storniolo AM, Kerber C, Seagren S, Berson A and Howell SB: Rapid superselective high-dose cisplatin infusion for advanced head and neck malignancies. Head Neck 14(5): 364 371, 1992. PMID: 1399569, DOI: 10.1002/hed.2880140505

32 Gemmete JJ: Complications associated with selective high-dose intraarterial cisplatin and concomitant radiation therapy for advanced head and neck cancer. J Vasc Interv Radiol 14(6): 743748, 2003. PMID: 12817041, DOI: 10.1097/01.RVI.00000799 83.80153 .90

33 Reuther T, Schuster T, Mende U and Kübler A: Osteoradionecrosis of the jaws as a side effect of radiotherapy of head and neck tumour patients - a report of a thirty-year retrospective review. Int J Oral Maxillofac Surg 32(3): 289-295, 2003. PMID: 12767877, DOI: $10.1054 /$ ijom.2002.0332
34 Lee IJ, Koom WS, Lee CG, Kim YB, Yoo SW, Keum KC, Kim GE, Choi EC and Cha IH: Risk factors and dose-effect relationship for mandibular osteoradionecrosis in oral and oropharyngeal cancer patients. Int J Radiat Oncol Biol Phys 75(4): 1084-1091, 2009. PMID: 19327914, DOI: 10.1016/ j.ijrobp.2008.12.052

35 Peterson DE, Doerr W, Hovan A, Pinto A, Saunders D, Elting LS, Spijkervet FK and Brennan MT: Osteoradionecrosis in cancer patients: The evidence base for treatment-dependent frequency, current management strategies, and future studies. Support Care Cancer 18(8): 1089-1098, 2010. PMID: 20526784, DOI: $10.1007 / \mathrm{s} 00520-010-0898-6$

36 Schuurhuis JM, Stokman MA, Roodenburg JL, Reintsema H, Langendijk JA, Vissink A and Spijkervet FK: Efficacy of routine pre-radiation dental screening and dental follow-up in head and neck oncology patients on intermediate and late radiation effects. A retrospective evaluation. Radiother Oncol 101(3): 403-409, 2011. PMID: 22001103, DOI: 10.1016/j.radonc.2011.09.018

37 Gomez DR, Estilo CL, Wolden SL, Zelefsky MJ, Kraus DH, Wong RJ, Shaha AR, Shah JP, Mechalakos JG and Lee NY: Correlation of osteoradionecrosis and dental events with dosimetric parameters in intensity-modulated radiation therapy for head-and-neck cancer. Int J Radiat Oncol Biol Phys 81(4): e207-213, 2011. PMID: 21570202, DOI: 10.1016/j.ijrobp. 2011.02.003
Received January 21, 2019

Revised February 11, 2019

Accepted February 14, 2019 